\title{
PERANCANGAN MESIN EKSTRUSI UNTUK DAUR ULANG SAMPAH PLASTIK BERBENTUK SILINDER
}

\author{
Budhi Martana $^{1 凶}$, Sigit Pradana ${ }^{2}$, Muhammad Arifudin Lukmana ${ }^{3}$ \\ ${ }^{1,2,3}$ Program Studi Teknik Mesin, Fakultas Teknik, Universitas Pembangunan Nasional Veteran Jakarta \\ Jalan R.S. Fatmawati, Pondok Labu, Jakarta Selatan 12450 \\ ${ }^{\square}$-mail :budhi.martana@upnvj.ac.id
}

\begin{abstract}
Plastic is a material that is very often used in everyday life. Due to the ease in the process of creating plastics with chemical substances and plastic's practical use, plastic has become very beneficial for people. The purpose of this research is to design an extruder in order to produce a cylindrical product (filament), so that it can be applied to the community as an effort to reduce plastic waste. The research method used is development research with the determination of several variables, namely: control variables in the form of plastic material with the type of PET and HDPE, the independent variables which are the temperature and engine speed (rpm), and the dependent variable which is the time needed to produce the product. The results obtained for the PET type plastic have the characteristics of fast, fluid, and runny, the results are discontinuous (discontinuous), brittle (brittle), for HDPE it has the characteristics of liquid and hard, also continuous, the resulting surface looks rough with flexible plastic properties, strong and elastic, while for the mixture of PET and white HDPE, the characteristics are liquid, and continuous. This mixture of PET and HDPE has a long drying time of up to 1350 seconds.
\end{abstract}

Keywords: Plastic waste, PET, HDPE, Extrusion.

\begin{abstract}
Abstrak
Plastik merupakan bahan yang amat sering digunakan dalam kehidupan sehari-hari, karena kemudahan dalam pembuatan bahan kimia menjadi plastik dan penggunaannya yang praktis membuat orang menjadikan plastik sebagai pilihan. Tujuan penelitian ini adalah melakukan perancangan ekstruder dalam rangka menghasilkan produk berbentuk silinder (filament), sehingga dapat diterapkan kepada masyarakat sebagai salah satu upaya pengurangan sampah plastik. Metode penelitian yang digunakan adalah riset pengembangan dengan penetapan beberapa variabel, yaitu: variabel kontrol berupa bahan plastik dengan jenis PET, dan HDPE, variabel bebas adalah temperatur dan putaran mesin (rpm), dan variabel terikat adalah waktu yang dibutuhkan dalam menghasilkan produk. Hasil penelitian yang diperoleh untuk plastik jenis PET memiliki karakteristik cepat cair dan encer, hasil terputus-putus (diskontinu), getas (rapuh), untuk HDPE memiliki karakteristik cair dan keras, hasil kontinu, permukaan yang dihasilkan terlihat kasar dengan sifat plastik lentur, kuat dan elastis, sedangkan untuk campuran PET dan HDPE putih dihasilkan karakteristik cair, dan kontinu. Campuran PET dan HDPE ini memiliki waktu untuk pengeringan yang cukup lama mencapai 1350 detik.
\end{abstract}

Kata kunci: Sampah plastik, PET, HDPE, Ekstrusi

\section{Pendahuluan}

Sampah telah menjadi masalah serius bagi lingkungan hidup diseluruh dunia dan berkaitan erat dengan kehidupan manusia sehari-hari. Setiap orang tidak terlepas dengan permasalahan sampah, sebagai pihak penghasil sampah. Sampah merupakan sesuatu yang tidak dipakai, tidak disenangi dan harus dibuang, yang dihasilkan dari aktivitas penduduk semakin meningkat seiring dengan berkembangnya populasi penduduk di Indonesia. Sampah dapat dikelompokkan menjadi (1) bahan berbahaya dan beracun, (2) mudah terurai, (3) dapat digunakan kembali, (4) dapat didaur ulang, dan (5) jenis sampah lainnya (1). Saat ini jumlah timbulan sampah plastik yang dihasilkan mencapai sekitar 1,3 
miliar ton setiap tahunnya dan pada tahun 2025 diperkirakan mengalami peningkatan hingga 3,4 miliar ton (2).

Produksi sampah yang dihasilkan akhirakhir ini semakin meningkat, salah satunya adalah jenis sampah plastik. Kontribusi sampah plastik sebesar 14,7\% per tahun, sehingga sampah plastik menjadi penyumbang terbesar kedua setelah sampah organik (3).

Tidak dapat dipungkiri plastik adalah salah satu jenis material yang sangat sering dipergunakan, karena proses pembuatannya yang mudah, harga yang murah, sifat plastik yang mudah dibentuk, tahan lama. Bahan plastik sulit tergantikan dengan bahan lainnya untuk berbagai keperluan sehari-hari, seperti untuk penggunaan kemasan makanan, alat-alat rumah tangga, mainan anakanak, elektronik, dan komponen kendaraan bermotor.

Teknologi ekstrusi merupakan proses pembentukan material dengan cara dipanaskan sampai mencapai titik leleh. Selanjutnya dialirkan ke cetakan oleh screw untuk menghasilkan material berpenampang silinder sesuai dengan bentuk lubang cetakan (die).

Proses ekstrusi adalah proses continue yang menghasilkan beberapa produk seperti, film plastik, tali rafia, pipa, pelet, lembaran plastik, fiber, filamen, selubung kabel, dan beberapa produk lainnya.

Penelitian ini bertujuan untuk melakukan perancangan ekstruder dalam rangka menghasilkan produk berbentuk silinder (filament), sehingga dapat diterapkan kepada masyarakat sebagai salah satu upaya pengurangan sampah plastik.

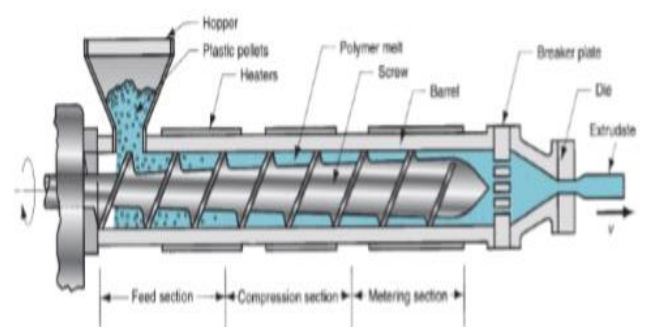

Gambar 1. Komponen dan Fitur Mesin Ekstruder Plastik

\section{Metode Penelitian}

Penelitian ini dilaksanakan dengan beberapa tahapan, sebagai berikut: (1) tahap perancangan (desain), (2) tahap pembuatan alat, dan (3) tahap pengujian. Sedangkan bahan dan alat yang digunakan pada penelitian ini, yaitu: (1) bahan plastik jenis PET (polyethylene terephthalate), dan HDPE (high density polyethylene), (2) heat plastic extruder, (3) cetakan, (4) timbangan, (5) gelas ukur, dan (6) Stopwacth.

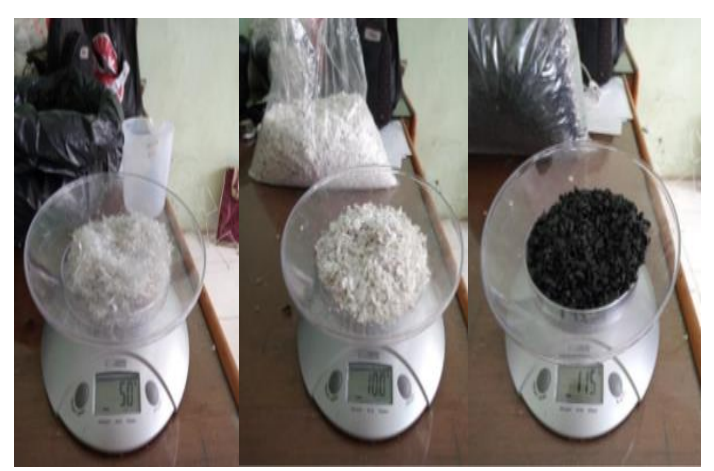

Gambar 2. Bahan plastik PET, HDPE putih dan HDPE hitam

Metode penelitian yang digunakan adalah riset pengembangan yang digambarkan seperti terlihat pada gambar 3 .

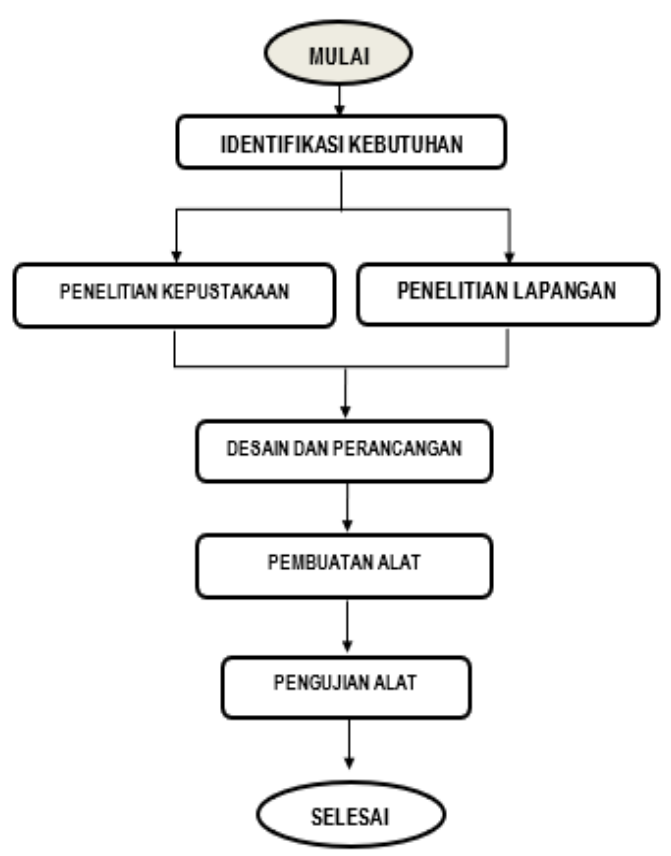

Gambar 3. Diagram Alir Penelitian 
Prosedur yang digunakan dalam pengujian ini, sebagai berikut: (1) ambil bahan sesuai dengan kebutuhan yang diperlukan untuk pengujian, (2) timbang bahan sesuai kebutuhan, (3) hidupkan atau jalankan heat plastic extruder, (4) aktifkan indikator temperatur dan indikator rotor, (5) atur (setting) temperatur sesuai dengan temperatur yang diingikan, (6) masukkan bahan yang akan dilelehkan melalui hopper ekstruder, (7) hitung waktu yang dibutuhkan untuk melelehkan sampai produk dihasilkan dengan menggunakan stopwacth, dan (8) lakukan pengamatan pada hasil proses sesuai dengan jenis bahan yang diproses.

Variabel yang ditentukan pada penelitian ini, yaitu: (1) variabel kontrol adalah bahan plastik, (2) variabel bebas adalah temperatur dan putaran mesin (rpm), dan (3) variabel terikat adalah waktu yang dibutuhkan untuk untuk mengahsilkan produk berbentuk silinder (filament).

\section{Hasil dan Pembahasan}

Perancangan mesin ekstruder ini dilatarbelakangi oleh adanya keiinginan untuk proses reduksi sampah plastik yang semakin banyak saat ini. Tahap awal dalam perancangan yaitu melakukan identifikasi kebutuhan mesin yang diinginkan, dan konsep-konsep yang terkait dengan penelitian yang dilakukan. Selama proses identifikasi kebutuhan tersebut, dilakukan pengumpulan data, penelitian kepustakaan dan penelitian lapangan, kemudian data tersebut divalidasi untuk mengetahui spesifikasi suatu produk mesin ekstruder untuk daur ulang sampah plastik sesuai dengan kebutuhan.

Tabel 1. Spesifikasi Mesin Ekstruder

\begin{tabular}{lll}
\hline No & Ketentuan & Spesifikasi \\
\hline 1 & Produk Input & Cacahan Plastik \\
2 & Produk Output & Filamen \\
3 & Dimensi Ouput & Diameter 1,50 mm \\
\hline
\end{tabular}

\begin{tabular}{lll}
\hline 4 & Dimensi Mesin & $85 \times 50 \times 120 \mathrm{~mm}$ \\
5 & Berat & $35 \mathrm{~kg}$ \\
6 & Kapasitas & $5-10 \mathrm{~kg} / \mathrm{jam}$ \\
7 & Diameter Screw & $27,5 \mathrm{~mm}$ \\
8 & Panjang Screw & $600 \mathrm{~mm}$ \\
9 & Material Screw & Stainless Steel 304 \\
& dan Barrel & \\
10 & Material Hopper & Baja Lembaran \\
11 & Material Rangka & Baja Profil \\
12 & Daya Motor & 0,75 kW \\
13 & Daya Pemanas & $650 \mathrm{Watt}$ \\
\hline
\end{tabular}

Spesifikasi yang sudah terdefinisi merupakan sebagai acuan untuk dikembangkan kembali dan melanjutkan tahap perancangan konsep.

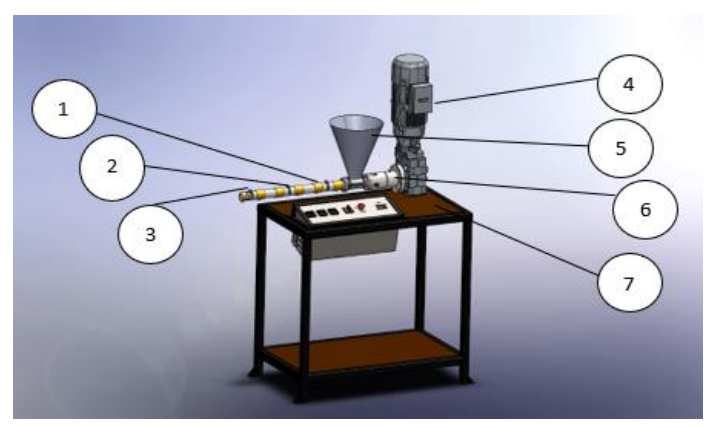

Gambar 4. Desain Mesin Ekstruder

Keterangan: (1) Barrel dan Screw; (2) Band Heater; (3) Nozel; (4) Motor Listrik; (5) Hopper; (6) Bearing; dan (7) Rangka.

Penelitian kepustakaan diperlukan untuk mengobservasi lebih lanjut mengenai topik terkait, misalnya mengobservasi mesin ekstruder yang sudah ada dan teruji, informasi tersebut dapat dijadikan dasar membuat rancangan/desain. Pembuatan rancangan mesin ekstruder untuk daur ulang sampah plastik berbentuk silinder menggunakan Computer Aided Design (CAD) dengan segala parameter yang sudah ditentukan sebelumnya. Perancangan ini didasarkan pada spesifikasi mesin ekstruder sesuai identifikasi kebutuhan yang telah dilakukan.

Sampah plastik PET dan HDPE. HDPE yang digunakan, yaitu HDPE berwarna putih, jenis ini lebih elastis dibandingkan 
yang berwarna hitam. Jenis HDPE putih dari botol-botol bekas seperti botol bekas sabun, shampoo, tinta, dan obat. Sedangkan jenis HDPE berwarna hitam, lebih getas dibandingkan yang berwarna putih, jenis ini yang sudah didaur ulang dan digunakan kembali, seperti ember, bak mandi atau kolam air, botol oli, dan pipa kabel.

Tabel 2. Volume dan massa plastik

\begin{tabular}{llll}
\hline No & Nama & Volume & Massa \\
\hline 1 & PET & $200 \mathrm{ml}$ & $50 \mathrm{gr}$ \\
2 & HDPE Putih & $200 \mathrm{ml}$ & $90 \mathrm{gr}$ \\
3 & HDPE Hitam & $200 \mathrm{ml}$ & $115 \mathrm{gr}$ \\
\hline
\end{tabular}

Tabel 3. Data pengujian PET bening

\begin{tabular}{llll}
\hline No & Tempartur & FR $(\boldsymbol{\omega})$ & Waktu \\
\hline 1 & $280^{\circ} \mathrm{C}$ & $35 \mathrm{rpm}$ & 453 \\
2 & $300^{\circ} \mathrm{C}$ & $40 \mathrm{rpm}$ & 330 \\
\hline
\end{tabular}

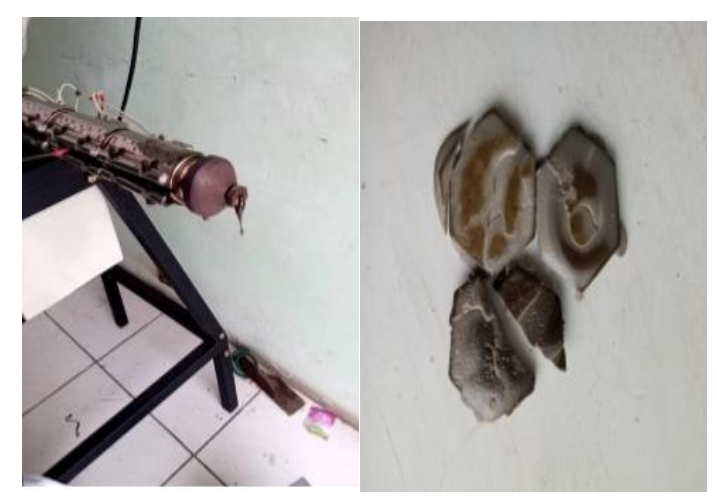

Gambar 5. Hasil pengujian sampel PET

Berdasarkan hasil pengujian pada tabel 3, dimana proses pengujian dilakukan 2 (dua) kali dengan volume sebesar $200 \mathrm{ml}$ dan massa plastik 50 gr. Hasil pengujian menunjukkan material atau bahan, memiliki karakteriktis ketika keluar dari heater ekstruder, berbentuk cair, masih bersifat encer yang membuat keluaran hasil terputus-putus (diskontinu), sifat plastik getas (rapuh) dengan tampilan solid atau padat dengan permukaan licin.

Tabel 4. Data pengujian HDPE putih

\begin{tabular}{llll}
\hline No & Tempartur & FR $(\boldsymbol{\omega})$ & Waktu \\
\hline 1 & $280^{\circ} \mathrm{C}$ & $35 \mathrm{rpm}$ & 1200 \\
2 & $300^{\circ} \mathrm{C}$ & $40 \mathrm{rpm}$ & 960 \\
\hline
\end{tabular}

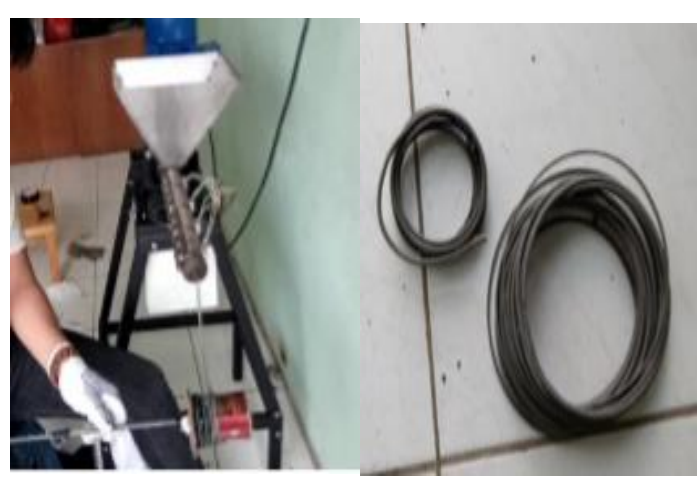

Gambar 6. Hasil pengujian sampel HDPE putih Berdasarkan hasil pengujian pada tabel 4 dan gambar 5, diperoleh hasil pengujian menunjukkan material atau bahan, dihasilkan karakteriktis material yang dilelehkan cepat keluar dari mulut heater mesin ekstruder, berbentuk cair dan mengeras yang membuat keluaran hasil kontinu, Permukaan yang dihasilkan terlihat kasar dengan sifat plastik lentur, kuat dan elastis.

Tabel 5. Data pengujian HDPE hitam

\begin{tabular}{llll}
\hline No & Tempartur & FR $(\boldsymbol{\omega})$ & Waktu \\
\hline 1 & $280^{\circ} \mathrm{C}$ & $35 \mathrm{rpm}$ & 650 \\
2 & $300^{\circ} \mathrm{C}$ & $40 \mathrm{rpm}$ & 740 \\
\hline
\end{tabular}

Berdasarkan hasil pengujian pada tabel 5 dan gambar 6 , diperoleh hasil pengujian menunjukkan sifat plastik cair, sehingga keluaran tidak kontinu. Waktu yang diperlukan untuk mengeringkan dengan temperatur $300^{\circ} \mathrm{C}$ dan putaran $35 \mathrm{rpm}$ mencapai 650 detik sedangkan dengan temperature $280^{\circ} \mathrm{C}$ dan putaran $40 \mathrm{rpm}$ diperlukan waktu selama 740 detik.

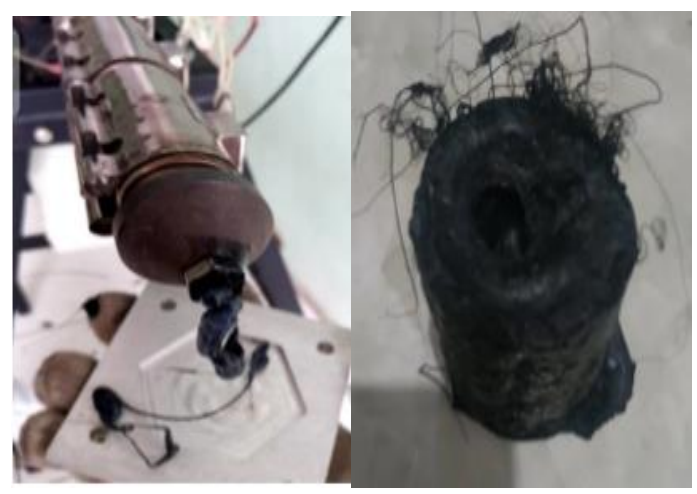

Gambar 7. Hasil pengujian sampel HDPE hitam 
Sifat fisik getas dan sedikit elastis. Kelebihan jenis HDPE hitam ini ketikan keluar dari heater ekstruder bersifat cair, encer, mudah untuk dilakukan proses pengepresan dan jika sudah kering bentuk padat dan permukaan licin. Kekurangannya adalah tidak kontinu, elastisitas sangat rendah, dan getas.

Tabel 6. Data pengujian campuran 100 gr PET dan 100 gr HDPE putih

\begin{tabular}{llll}
\hline No & Tempartur & FR $(\omega)$ & Waktu \\
\hline 1 & $280^{\circ} \mathrm{C}$ & $40 \mathrm{rpm}$ & 1350 \\
\hline
\end{tabular}

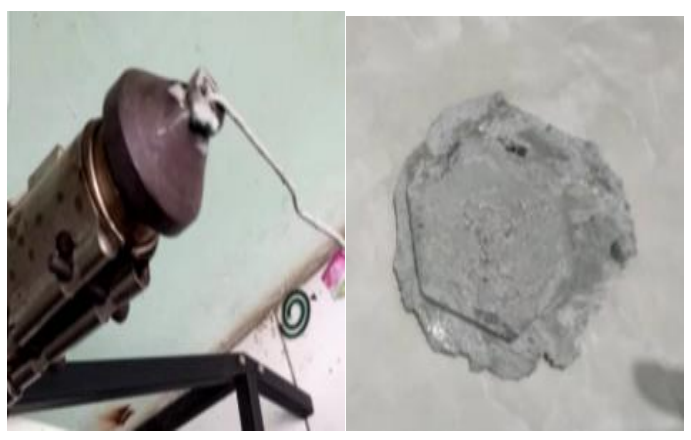

Gambar 8. Hasil pengujian sampel campuran PET dan HDPE putih

Berdasarkan hasil pengujian pada tabel 6 , dimana proses pengujian dilakukan 1 (satu) kali. Variabel kontrol campuran plastik PET bening dan HDPE hitam dengan massa plastik 100 gr, variabel bebas $280^{\circ} \mathrm{C}$ dan putaran $40 \mathrm{rpm}$. Hasil pengujian menunjukkan material karakteriktis material yang dilelehkan ketika baru keluar dari heater dalam bentuk cair, dan proses keluaran bersifat kontinu. Campuran ini memiliki waktu untuk mengeringkan cukup lama mencapai 1350 detik. Keunggulan campuran PET dan HDPE ini, yaitu ketika keluar dari heater ekstruder memiliki bentuk fisik padat basah, mudah dicetak atau dipress menjadi produk tertentu sesuai dengan yang diinginkan, dan cepat kering.

\section{Kesimpulan}

Perancangan dan pengujian mesin ekstruder menjadi suatu alternatif dalam menangani permasalahan sampah plastik. Rancangan mesin ekstruder yang dihasilkan memiliki dimensi mesin $85 \mathrm{x}$ $50 \times 120 \mathrm{~mm}$, dengan diameter output $1,50 \mathrm{~mm}$. Hasil pengujian yang dilakukan dengan memfaatkan sampah plastik PET dan HDPE, untuk PET memiliki karakteristik sifat fisik cair, bersifat encer, elastistas plastik rendah dan getas serta memerlukan waktu proses selama 453 detik. Sedangkan untuk HDPE putih sifat fisik adalah padat basah, elastisitas tinggi, dan waktu proses mencapai 1200 detik. Untuk material campuran PET dan HDPE putih memiliki sifat fisik padat basah, cepat kering, dan waktu proses mencapai 1350 detik.

\section{Ucapan Terima Kasih}

Terima kasih disampaikan kepada LPPM UPN Veteran Jakarta yang telah mendanai kegiatan Riset Unggulan Program Studi Tahun Anggaran 2020.

\section{Daftar Pustaka}

[1] Kementerian Lingkungan Hidup dan Kehutanan. 2012. Peraturan Pemerintah Nomor 81 Tahun 2012 tentang Pengelolaan Sampah Rumah Tangga dan Sampah Sejenis Sampah Rumah Tangga.

[2] Kaza, S., Yao L., Bhada-Tata C., Woerdan F.V. 2018. What a Waste 2.0: A Global Snapshot of Solid Waste Management to 2050. Urban Development. Washington, DC: World Bank.

[3] Kholidah, N., Faizal, M., Said, M. 2018. Polystyrene P lastic Waste Conversion into Liquid Fuel with Catalytic Cracking Process Using $\mathrm{Al} 2 \mathrm{O} 3$ as Catalyst. Science \& Technology Indonesia, 3, 1- 6.

[4] Mahmudi A., Londa P., 2017. Optimasi Penerapan Teknologi Ekstrusi pada Prototipe Mesin Daur Ulang Limbah Styrofoam. Jurnal 
Teknik Mesin Rotasi. Vol. 19 No. 2. 92-96

[5] Groover, M. P. 2010. Fundamentals of Modern Manufacturing 4thEd. USA: John Wiley \& Sons, Inc.

[6] Jambeck, J.R., Geyer, R., Wilcox, C., Siegler, T.R., Perryman, M., Andrady, A., Narayan, R., and Law, K.L. (2015). Plastic Waste Inputs from Land into The Ocean. New York: Science Magazine.

[7] Purwaningrum, P. (2016). Upaya Mengurangi Timbulan Sampah Plastik di Lingkungan, JTL Vol 8 No.2, Desember 2016, 141-147 